\title{
La conservación del arte urbano y los derechos de autor
}

\author{
Eva Sòria Puig | Investigadora especialista en propiedad intelectual \\ URL de la contribución <www.iaph.es/revistaph/index.php/revistaph/article/view/4936>
}

La conservación artística tiene como objetivo preservar los bienes culturales y los elementos materiales que tienen valor artístico, histórico o científico. Los bienes culturales son un legado irreemplazable que debe ser preservado para el estudio y el disfrute de futuras generaciones. Cuando un bien se deteriora, el restaurador interviene bien aplicando técnicas de conservación preventiva, o si procede, según sea la naturaleza de la obra, reintegrando su superficie con técnicas reversibles y respetuosas con los materiales, para, en la medida de lo posible, recuperar aspecto original de la obra.

Muchas de las obras intervenidas son antigüedades (pinturas sobre tela que por su envejecimiento o mani- pulación han sufrido daños en su capa pictórica o en su soporte). Pero, en ocasiones, las obras intervenidas son obras contemporáneas, o relativamente recientes, que, o bien por el deterioro de sus materiales o bien por los daños causados por condiciones medioambientales, necesitan una restauración.El grafiti, por su naturaleza y su exposición a la intemperie y, por lo tanto, a condiciones medioambientales extremas (luz solar, lluvia, cambios de temperatura, vandalismo) se deteriora rápidamente y es susceptible de ser intervenido para garantizar su conservación. Si no han pasado más de setenta años desde el fallecimiento de su autor, el arte urbano, como cualquier obra, estará protegido por el derecho de propiedad intelectual.

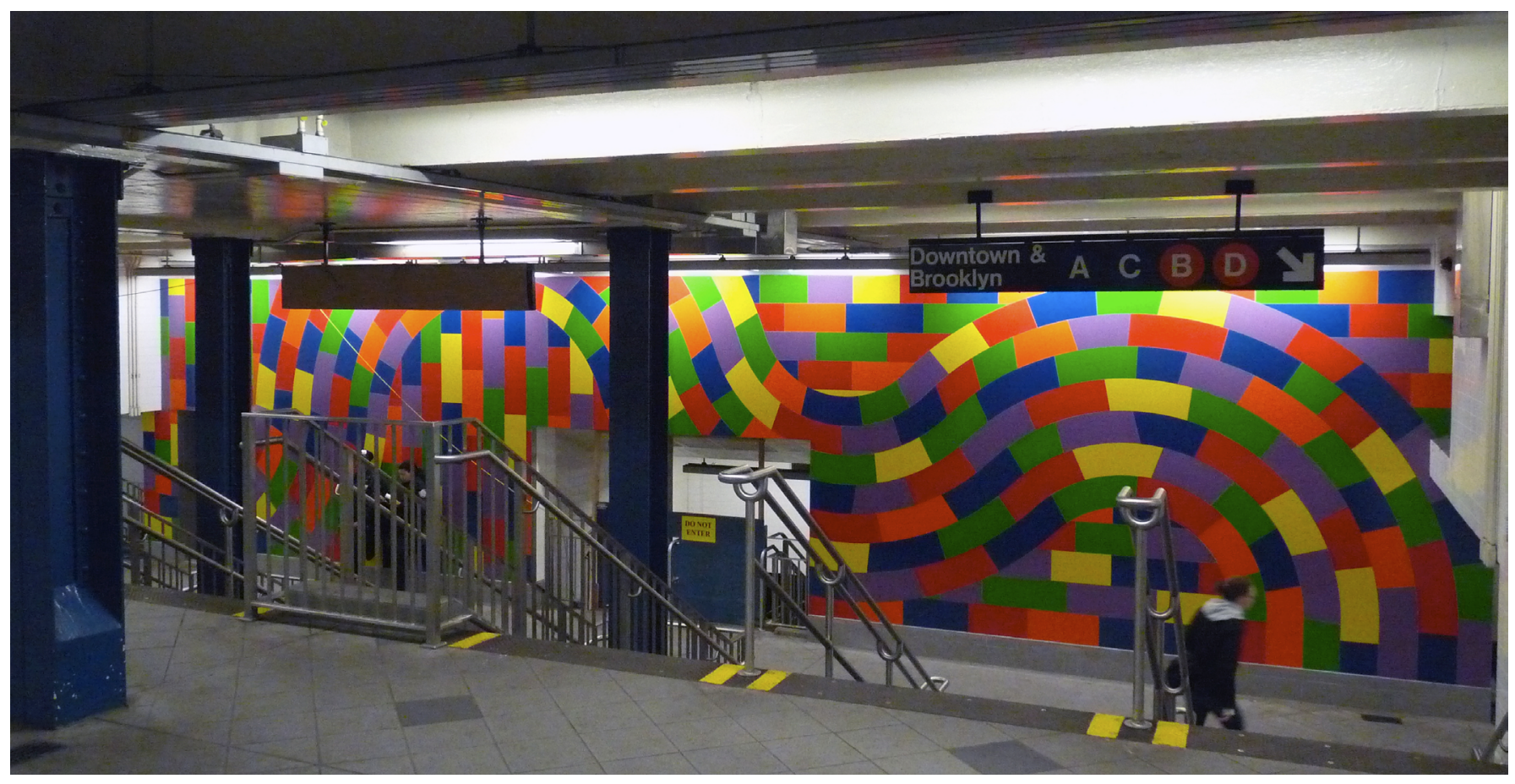

Sol LeWitt | foto karlnorling 
La propiedad intelectual tiene por objetivo conferir derechos a los autores de aquellas creaciones que la ley considera obras objeto de propiedad intelectual. El concepto de obra protegida no siempre coincide con el de obra artística: para que una obra tenga derechos de propiedad intelectual, deberá ser original (entendiendo por original que el autor ha podido tomar "decisiones libres y creativas"1); tendrá que estar plasmada en un soporte tangible o intangible (la ley de propiedad intelectual no protege las ideas sino la expresión de las ideas); y, finalmente, las obras tendrán que tener un autor, es decir, ser fruto del ingenio humano, no pueden ser producto de las acciones de un animal ni tampoco de una máquina.

Si una creación cumple los requisitos para ser considerada obra protegible, su titular (el autor, sus herederos o aquel a quien el autor haya cedido sus derechos exclusivos) podrá impedir a un tercero copiar, reproducir, distribuir o transformar la obra sin un permiso previo. En los derechos de autor se distinguen los derechos morales, que los autores conservarán sobre sus obras y que incluyen, principalmente, el derecho de autoría y el de integridad, es decir, el derecho a impedir que un tercero modifique la obra sin su permiso; y los derechos patrimoniales, por una parte aquellos que no permiten controlar los usos de la obra pero que representan remuneraciones para el autor (como el derecho de participación y el derecho de copia privada), y por otra los derechos exclusivos (permiten al titular autorizar o prohibir la copia, reproducción, comunicación pública y transformación de su obra).

Este "monopolio" del uso de las obras que conferimos al autor tiene límites y excepciones: son los casos en que cualquier persona podrá utilizar la obra sin necesidad de solicitar el consentimiento del titular de los derechos. Estos límites están pensados en situaciones en que otros derechos tienen prioridad sobre los derechos de propiedad: el derecho a la libertad de expresión y crítica; el derecho a la información; a la educación o a la investigación, entre otros. Pero estos límites siempre se interpretan de forma un tanto encorsetada y bajo consideraciones muy restringidas.
El derecho de autor ser refiere a corpus mechanicum para hablar del soporte físico de la obra (sobre el que se realiza la intervención) y a corpus mysticum para referirse al "bien" sobre el que el autor retiene los derechos de propiedad intelectual. Es decir, si yo hago una foto de una obra protegida por la ley de propiedad intelectual y la publico sin permiso de su autor, estoy ejerciendo un derecho que no me corresponde sobre el corpus mysticum sin afectar al corpus mechanicum.

Cuando un restaurador de arte interviene en una obra de arte contemporáneo, el aspecto formal de la obra se modifica. Si comparamos las fotos del antes y después de la intervención (como hacemos a menudo para comparar el impacto de la restauración) veremos que la obra ha "recuperado" a su aspecto original gracias a la intervención técnica de un restaurador. Ahora bien: ¿es el restaurador el titular de los derechos de autor de la obra restaurada?

Volvamos a las fotos del antes y el después. Está claro que para reproducir la primera (la previa a la restauración) deberemos contar con el permiso del autor o de sus herederos, a no ser que nos encontremos amparados por algún límite (por ejemplo no debemos pedir permiso si la obra se publica en una tesis doctoral, pero sí para su publicación en un libro divulgativo o en el catálogo de una exposición).

Pero, ¿que pasará con las fotos de la obra después de su intervención? ¿Podremos publicarlas sin permiso del autor? ¿Estaremos delante de una obra derivada? ¿De una obra compuesta? ¿Cumplirá la obra con el requisito de originalidad que confiera al restaurador derechos de propiedad intelectual sobre el resultado de la intervención de esta obra? Recordemos que tendremos originalidad si se han tomado "decisiones libres y creativas". ¿Se pueden tomar decisiones "libres y creativas" ejerciendo un trabajo técnico? Estas son las preguntas que nos deberemos formular para encontrar respuestas a la intersección entre la ley de propiedad intelectual y el resultado de una restauración. La respuesta cambiará según las circunstancias de cada caso. 


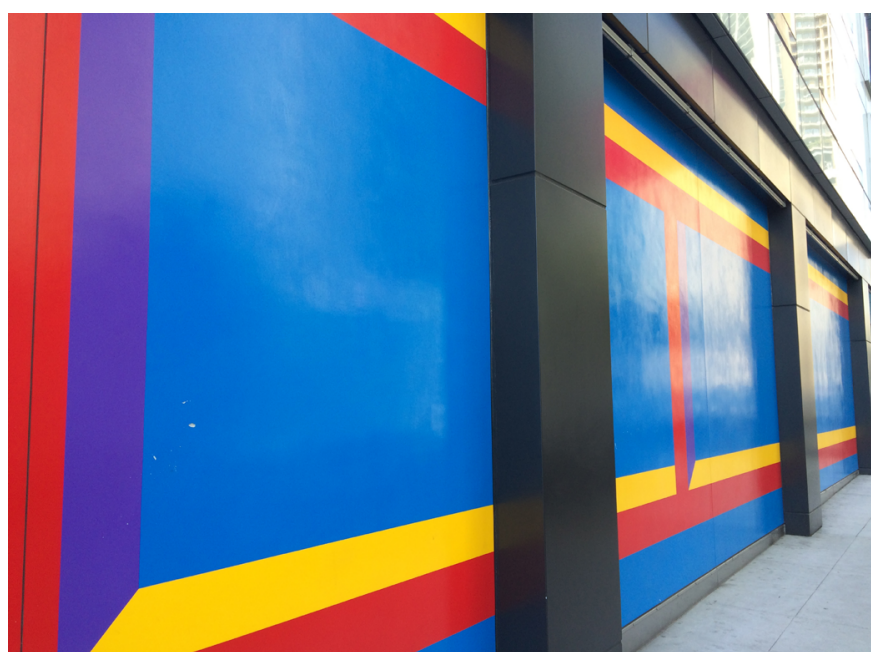

Wall Drawing \#1012 de Sol LeWill en San Francisco | foto rocor

El caso del arte urbano presenta una doble complejidad en cuanto a los derechos de autor de sus intervenciones. En primer lugar, por encontrarse en el espacio público: el derecho a panorama es uno de los límites que permite la reproducción de las obras que se encuentran en la vía pública sin permiso de sus titulares. Pero este derecho, como el resto, también tiene matices. ¿Qué es exactamente la vía pública? ¿Qué pasa cuando este límite se ejerce de manera que causa un perjuicio injustificado a su autor, por ejemplo cuando se usa para realizar una campaña de publicidad??

El caso de los murales de Sol LeWitt (Hartford, Connecticut, 1928-New York, 2007) es especialmente interesante. Respecto a la conservación de sus obras, LeWitt expresó su voluntad de que sus trabajos siempre parecieran como recién pintados, sin que les afectase el paso del tiempo o la intemperie, a las que él llamaba "falsificaciones del tiempo"3 ya que el cambio en los materiales afecta a la interpretación de sus obras. Las cuestiones que presenta este caso en particular nos interrogan sobre si lo que se necesita preservar es el concepto más que la materialidad de la obra y si, en el caso que la restauración permita tomar decisiones libres y creativas, el técnico restaurador podría reclamar algún derecho sobre su corpus mechanicum.
Todas son cuestiones interesantísimas sobre la intersección entre arte urbano, conservación y propiedad intelectual, y merecen se estudiadas en profundidad.

\section{NOTAS}

1. Así lo determina "Painer", una sentencia del Tribunal de Justicia de la Union Europea Painer (1/12/2011, C-145/10, ECLI:EU:C:2011:798).

2. Así sucedió con el a "El Muelle" (seudónimo de Juan Carlos Argüello, Madrid, 1965-1995) que pasaría de ser multado por pintar en la famosa escultura El oso y el madroño de la Puerta del Sol (Antonio Navarro, Villena, 1906-1983) a aparecer en folletos de promoción turística de Madrid.

3. Polkownik, C. Conceptual and Ephemeral Art: Conservation Issues $18 \mathrm{~J}$. Art Crime 83 (2017). 